\title{
NOVAS REALIDADES NO ENSINO SUPERIOR A DISTÂNCIA: A INCLUSÃO DE UNIVERSITÁRIOS COM DEFICIÊNCIA
}

\author{
Andreia Ines Dillenburg ${ }^{\mathrm{i}}$ \\ Andrea Forgiarini Cecchin ${ }^{\text {ii }}$
}

Resumo: O presente artigo discorre sobre a inclusão de pessoas com deficiência no Curso de Pedagogia a distância da Universidade Federal de Santa Maria a partir implementação da Resolução 011/2007. Procura tratar dos desafios encontrados pela coordenação do curso para a inclusão de estudantes com deficiência e das estratégias adotadas para dar conta desse processo. Atualmente o curso possui cinco estudantes com deficiência matriculados em um universo de 399 estudantes. Os caminhos metodológicos foram pautados em uma abordagem qualitativa caracterizada como descritiva, possuindo como objetivo primordial a descrição das características de determinada população ou fenômeno $\mathrm{O}$ principal expediente utilizado foi a tentativa de despertar um olhar atento aos estudantes que acessam a universidade respeitando as suas demandas e peculiaridades, evitando considerá-lo como um número, um dado estatístico.

Palavras-chave: Educação a distância. Inclusão. Gestão Educacional.

\section{NEW REALITIES IN THE DISTANCE HIGHER EDUCATION: THE INCLUSION OF COLLEGE DEGREES WITH DISABILITIES}

\begin{abstract}
The current article intends to present actions, challenges and legislations that have permeated the inclusion processes in the Distance Pedagogy Course in the Federal University of Santa Maria - RS, Brazil from the implementation of the resolution 011/2007. Nowadays, the course has six included students in a universe of 399 ones. The course team - coordination, professors and tutors - have made efforts in order that the process of inclusion handle not only the permanence of the students, but also the quality of the teaching process of these individuals. It is understood that since it is guaranteed the access to disabled people, it is necessary to think actions and debate the search for the permanence and the affective learning of these students, assuring the formation of an abled professional for the work marked. This article aims to focus on the challenges found by the course coordination regarding the inclusion of these students and the adopted strategies to handle this process. The main expedient used was the attempt of awakening an attentive look to the students that access the university, respecting their demands and peculiarities and avoiding considering them as number, a statistical data.
\end{abstract}

Keywords: Distance Education. Inclusion. Educational Administration. 


\section{Introdução}

$\mathrm{Na}$ atual conjuntura do sistema de ensino brasileiro compreende-se uma expansão no número de vagas. ofertadas no ensino superior. Movimento impulsionado por programas como Programa de Apoio a Planos de Reestruturação e Expansão das Universidades Federais -REUNI e o Programa Universidade Para Todos-PROUNI De acordo com o Censo da Educação Superior (2016) as instituições públicas aumentaram em 1,9\% no número de ingressantes. Compreendese que o cenário educacional não é isolado das demais situações do cotidiano, ao contrário, é possível verificar que busca, constantemente, adequar-se às novas regras globais. Com a competitividade do mercado de trabalho e falta de vagas, a qualificação profissional tem sido cada vez mais importante.

Nesse contexto, o entrelaçamento das questões econômicas, sociais e históricas permite verificar o quanto a Educação a Distância - EAD é de suma importância para a democratização do acesso ao ensino. De acordo com o relatório 2014 da Associação Brasileira de Educação a Distância-ABED ${ }^{\text {iii }}$ em 2014, os cursos de EAD somaram 3.868.706 matrículas, com 519.839 (13\%) nos cursos regulamentados totalmente a distância, 476.484 (12\%) nos cursos regulamentados semipresenciais ou em disciplinas EAD de cursos presenciais e 2.872.383 (75\%) nos cursos livres. A média geral foi de 154 matrículas por curso e de 16.053 matrículas por instituição formadora. A complexidade da modalidade a distância tem apresentado aos gestores desses cursos uma série de desafios, dentre eles, a inclusão da pessoa com deficiência.

Atualmente, o Curso de Pedagogia a distância da Universidade Federal de Santa Maria tem 399 estudantes regularmente matriculados, dos quais cinco pessoas com deficiência (três deficientes visuais, uma deficiente auditiva e um deficiente físico). A equipe do curso, gestores, professores e tutores, tem se organizado para realizar a acessibilidade metodológica para os acadêmicos. A operacionalização dessa sistemática, a criação de estratégias para que o processo possa promover qualidade de acesso e permanência a todos, têm sido um constante desafio. Neste sentido o objetivo deste artigo é apresentar as ações e desafios encontrados pela coordenação do curso para a inclusão destes estudantes e das estratégias adotadas para dar conta desse processo.

Para fundamentar este texto nos debruçamos sobre as políticas públicas que tratam desta temática, apresentando principalmente as leis vigentes em nosso país. Destaca-se a Lei $\mathrm{n}^{\circ}$ 13.146, de 6 de julho de 2015, denominada Lei Brasileira de Inclusão da Pessoa com Deficiência 
(Estatuto da Pessoa com Deficiência) e a Política Nacional de Educação Especial na Perspectiva da Educação Inclusiva de 2008 Complementaremos as questões relativas à educação a distância com autores referência na área como Belloni (1999, 2006), Corrêia (2007), Guarezi e Matos (2009), Lima (2010) e Nogueira (2016). No âmbito da inclusão foram utilizadas as contribuições de Garcia (2008), Manzini (2007), Siluk e Pavão (2012) e Sassaki (2009; 2010).

\section{Metodologia}

Os caminhos metodológicos foram pautados em uma abordagem qualitativa que se detém a investigar seus objetivos em suas qualidades, ações e não somente em números e percentuais. Para Gerhrdt, et al. (2009) a pesquisa qualitativa preocupa-se com aspectos da realidade que não podem ser quantificados, centrando-se na compreensão e explicação da dinâmica das relações sociais.

De acordo com Densin e Lincoln (2006), para compreender o fenômeno a partir do significado que as pessoas a ele conferem, a pesquisa qualitativa abrange uma postura interpretativa do mundo. Creswel (2007) corrobora essa ideia, ao defender que o ambiente natural é fonte direta de dados, sendo o pesquisador o principal instrumento na pesquisa qualitativa. Destaca, ainda, que nesta abordagem a preocupação com o processo se sobrepõe ao produto, dada a preocupação do pesquisador em apurar como o fenômeno se manifesta nas atividades, nas interações e nos procedimentos cotidianos.

Podemos classificar o estudo como descritivo, que de acordo com Creswel (2007) a grande contribuição desta modalidade de pesquisa é proporcionar reflexões sobre uma realidade que já ocorreu. A coleta de dados ocorreu ao longo de 3 semestres e os materiais de analise foram: gravação de formações e reuniões, feedbacks dos estudantes e os relatórios semestrais de professores, tutores a distância, presenciais e especializados. Para analisar todos os dados coletados foi utilizada a técnica de Análise de Conteúdo de Bardin. Caracterizando a técnica como um conjunto de procedimentos sistemáticos e objetivos de descrição do conteúdo das mensagens (Bardin, 2008).

\section{A educação a distância como ferramenta de inclusão social}

No território brasileiro a educação a distância passa a ser considerada uma modalidade de ensino a partir da Lei de Diretrizes e Bases da Educação Nacional (LDBN), Nº. 9394, de 1996 que, no Art. 80, determina que "o poder público incentivará o desenvolvimento e a veiculação de 
programas de ensino distância, em todos os níveis e modalidades de ensino, e de educação continuada" (BRASIL, 1996). No entanto, a regulamentação da EaD só ocorreu através do Decreto 5.622 de 19 de dezembro de 2005 que a caracteriza como modalidade educacional na qual a mediação didático-pedagógica nos processos de ensino e aprendizagem ocorre com a utilização de meios e tecnologias de informação e comunicação, ou, como atualmente chamamos, das Tecnologias Digitais da Informação e da Comunicação (TDIC).

No atual cenário educacional encontramos diversas instituições e propostas educacionais que oferecem cursos na modalidade a distância em diferentes níveis de ensino. Nessa modalidade, estudantes e professores desenvolvem atividades educativas em lugares ou tempos diversos. Especificamente sobre o ensino superior a distância, Maciel, Cechin e Nogueira (2012) afirmam que a educação a distância vem alterando o cenário do ensino formal da universidade e essa transformação vem, consequentemente, provocando uma mudança de percepção temporal, geográfica e humana.

Para autores referência na área como Belloni (1999) e Corrêa (2007) a EAD é uma modalidade de estudo complementar a era industrial e tecnológica sendo a sua estrutura definida pelos parâmetros do modelo industrial fordista. Compreendemos que a principal finalidade da implementação deste sistema é abranger quem está distante dos espaços de ensino convencionais, proporcionando a oportunidade de qualificação profissional a um público que, em outras épocas, esteve a margem do sistema de ensino. Isso faz parte de um grande movimento de expansão das possibilidades de acesso ao ensino superior, movimento que acompanha as questões políticas, econômicas e sociais da última década (Belloni, 1999, 2006 Corrêia, 2007, Guarezi e Matos, 2009, Lima, 2010).

A competitividade no mercado de trabalho, resultado da informatização e do desemprego tem aumentado as exigências para inserção dos trabalhadores. Belloni (2006, p. 9) apresenta a importância social da educação a distância para diferentes grupos:

Na sociedade contemporânea, das redes telemáticas e da realidade virtual, a educação tem de ser realmente para todos e não só para os jovens, com uso intensivo de tecnologia numa perspectiva humanística de educação para o desenvolvimento, para a solidariedade, para a cidadania.

Atualmente, a EAD é capaz de chegar a realidades antes não abrangidas pelos sistemas de ensino tradicionais, proporcionando um fenômeno de inclusão educacional e social. Nesta mesma linha, o Sistema Universidade Aberta do Brasil (UAB), instituído através do Decreto 5.800/06, de 8 de junho de 2006, tem como principal objetivo a expansão e a interiorização da Educação Superior pública no país. Esse sistema prioriza, em parceria com as universidades 
públicas, a criação de cursos de licenciatura e de formação inicial e continuada de professores para atuarem na Educação Básica. Atualmente cabe a Diretoria de Educação a Distância da Capes (DED/Capes) o acompanhamento e supervisão das atividades desenvolvidas na UAB, seja no âmbito das instituições, dos cursos ou dos polos de apoio presencial.

A Portaria $n^{\circ} 183$ de 21 de outubro de 2016 da Coordenação de Aperfeiçoamento de Pessoal de Nível Superior (CAPES), veio substituir a Resolução n ${ }^{\circ}$ 26, de 05 de junho de 2009 do Fundo Nacional de Desenvolvimento da Educação (FNDE) e determina quais as regras para pagamento das bolsas e quais as atribuições de cada um dos envolvidos no Sistema UAB: coordenadores, professores e tutores. Cada um desses sujeitos, ao desempenhar sua função com comprometimento, pode ter um papel fundamental na inclusão de um estudante.

Mesmo entre aqueles que transitam há algum tempo nos meios digitais é possível perceber que, ao encarar um processo de ensino em que todas as ações (com exceção das avaliações presenciais) e interações são realizadas no ambiente virtual, os desafios se multiplicam. A garantia de uma formação acadêmica que não seja inferior à oferecida na modalidade presencial é uma delas. Assim,

\footnotetext{
Um curso superior a distância não deve ter conteúdos curriculares reduzidos ou objetivos truncados. Enfim, todos os esforços e recursos disponíveis devem ser utilizados na educação a distância para que seja garantida uma formação de qualidade. Ao tempo em que se advoga para a educação à distância o mesmo status que a sociedade atribui à educação presencial, os especialistas na área reconhecem que o desafio torna-se ainda maior, pois, além das questões presentes na educação tradicional, a educação a distância envolve aspectos específicos, pelas condições criadas pelo distanciamento físico" (BRASIL, 2002, p. 10).
}

É necessário avaliar que, independente da modalidade na qual o curso é ofertado, das diferenças nos recursos, metodologias, mecanismos de gestão e avaliação, o conteúdo e a possibilidade de formação devem ser iguais para os estudantes tanto no presencial como no a distância. Na visão de Nogueira (2016), “já não cabe mais interpretar a EAD como uma opção que não garante uma educação de qualidade" (p. 105). No ponto de vista dessa autora, o ensino presencial também apresenta problemas, essa não é uma peculiaridade da modalidade a distância.

Compreende-se que a educação a distância necessita para além do processo de garantia de acesso das populações que não teriam a opção de escolarização, buscar alternativas que potencializem a formação de qualidade. Pensar em inclusão social neste cenário não restringe-se ao estudante que usufrui da vaga em uma instituição pública de ensino mas também toda a sociedade que terá a sua disposição um profissional com qualidade e potencial de melhoria na 
educação e demais segmentos sociais. Nesta direção a equipe e coordenação de um curso de graduação EaD deve constantemente reforçar a importância curricular e metodológica de um processo de ensino na modalidade. O que modifica é a modalidade e não a preocupação com o conteúdo, aprendizagem e a função social de uma formação superior.

\section{Inclusão de pessoas com deficiência no ensino superior a distância}

A educação a distância vem se firmando como uma alternativa para aqueles que buscam o ensino superior. Diferentes leis, decretos e portarias orientam as práticas da EaD e auxiliam as instituições na organização desta modalidade de ensino. A partir de uma retomada na legislação que orienta o Ensino Superior verificamos que a oferta nessa modalidade possui o mesmo amparo legal que a do ensino presencial.

Em se tratando da pessoa com deficiência, compreende-se que todos possuem o direito ao acesso à educação. Essa premissa já é apresentada, em 2007, no artigo 24 da Convenção sobre os Direitos das Pessoas com Deficiência validado no Brasil pelo Decreto n ${ }^{\circ} 6.949$, de 25 de agosto de 2009. Em alguns objetivos presentes nestes documentos são previstas ações específicas para a educação de pessoas com deficiência, determinando que todos tenham acesso ao sistema educacional em seus diferentes níveis de ensino, garantindo o aprendizado ao longo de toda a vida:

a. O pleno desenvolvimento do potencial humano e do senso de dignidade e autoestima, além do fortalecimento do respeito pelos direitos humanos, pelas liberdades fundamentais e pela diversidade humana;

b. O máximo desenvolvimento possível da personalidade, dos talentos e da criatividade das pessoas com deficiência, assim como de suas habilidades físicas e intelectuais;

c. A participação efetiva das pessoas com deficiência em uma sociedade livre (BRASIL, 2009, p. 11).

A temática da inclusão é abordada em diversas leis federais: a Constituição Federal de 1988, que aborda a importância da educação para todos; a Lei no 13.146, de 6 de julho de 2015, o estatuto da pessoa com deficiência que amplia direitos cíveis das pessoas com deficiência; a Lei de Diretrizes e Bases da Educação Nacional n 9394/96, que apresenta um capitulo exclusivo sobre a modalidade; o Plano Nacional de Educação - PNE/2014 - 2024, que possui uma meta e suas respectivas estratégias para a inclusão de pessoas com deficiência nas instituições de ensino e a Política Nacional de Educação Especial na Perspectiva da Educação Inclusiva de 2008, a qual institui e classifica o público-alvo da inclusão, com ênfase no ensino regular. 
De forma complementar e adicional a legislação vigente, a Universidade Federal de Santa Maria, desde o vestibular de 2008 possui a reserva de 5\% de suas vagas para pessoas com deficiência, amparada na Resolução 011/07 que atualmente destina-se aos processos seletivos referentes a graduação, nível médio e cursos técnicos, tanto presenciais quanto à distância. É possível perceber que há um grande movimento buscando garantir o acesso de pessoas com deficiência aos diferentes níveis e modalidades de ensino.

A expansão e interiorização através da educação a distância são estratégias para o alcance de metas nacionais e internacionais para a educação. Esse movimento tem gerado novas possibilidades e realidades, dentre elas, a soma de dois processos de inclusão: o social e o pedagógico. Sassaki (2010), ao apresentar a inclusão social como um processo que contribui para a construção de um novo tipo de sociedade, traz questões relacionadas ao acesso a espaços anteriormente segregativos e a uma mudança na mentalidade das pessoas em relação à deficiência.

Ao encontro disso, no atual cenário educacional, a Educação Especial vem passando por mudanças e por uma visível ampliação, redundando em novas políticas. Sobre isso, Garcia (2013, p. 101) nos diz que:

A política de educação especial no Brasil na última década ganhou contornos que merecem ser analisados por conta de suas mudanças conceituais e estruturais. Parte de tal movimento está relacionada à adoção de uma perspectiva inclusiva para a educação nacional, que ganhou definições particulares quando voltada aos sujeitos que constituem o público-alvo das políticas de educação especial.

Em função dessas novas políticas o curso de Pedagogia UAB/UFSM tem desenvolvido ações que procuram possibilitar o acesso de pessoas com deficiência ao Ensino Superior, tais como: adequação de materiais didáticos, encontros de formação com a equipe de professores e tutores a distância e seleção de tutores presenciais especializados para atender a esses estudantes.

\section{Inclusão de estudantes no curso de Pedagogia a distância: ações e desafios}

A Universidade Federal de Santa Maria obteve o credenciamento para oferta de Educação a distância através do Parecer MEC/CEN No 4208, de 17 de dezembro de 2004. O primeiro curso ofertado nessa modalidade foi o de Educação Especial. Atualmente, a instituição oferece treze cursos de graduação (sendo dez licenciaturas) e treze cursos de pós-graduação, atendendo 38 polos no Rio Grande do Sul e um polo no Paraná. 
O Curso de Pedagogia EAD foi criado em 2007, com oferta em nove polos do Rio Grande do Sul: Cruz Alta, Faxinal do Soturno, Restinga Seca, Santana do Livramento, São Lourenço do Sul, Sobradinho, Tapejara, Três de Maio e Três Passos. Desde sua criação, o curso teve novas ofertas em 2009, 2010, 2012, 2013, 2014 e 2016. Alguns polos deixaram de ser atendidos e foram substituídos por outros. Atualmente, o curso tem ofertas em andamento nos seguintes polos: Santana do Livramento, Sobradinho, Tapejara, Três de Maio, Três Passos, Cacequi, Palmeira das Missões, Jacuizinho, Encantado, São Francisco de Paula, Sapucaia do Sul e São Sepé. Já formou 597 estudantes. É o curso com o maior número de ofertas, que atende o maior número de estudantes na graduação a distância e, no último processo seletivo, foi o mais concorrido (em um dos polos a relação candidato/vaga chegou a 28 por um). Tem um corpo docente composto por 44 professores, todos com no mínimo pós-graduação lato sensu, um número significativo de doutores. Dispõe, ainda, de um corpo qualificado de tutores: muitos com mestrado, alguns com doutorado e todos com, no mínimo, especialização. A qualificação da equipe de trabalho, principalmente na área da educação amplia a qualidade metodológica e as possibilidades de melhoria nas ações pedagógicas do curso. A distribuição da equipe de trabalho também considera as especificidades de atuação/formação dos docentes e tutores.

Exemplificando, nos estágios curriculares a equipe é formada por profissionais que atuam ou atuaram na educação básica, as disciplinas de educação especial e inclusão são geridas por profissionais da área. O curso tem apresentado uma preocupação na escala da equipe de profissionais que atuarão com os estudantes que ingressam, com acompanhamento e reuniões constantes para prevenir problemas de comunicação, evasão e repetências. A importância do acompanhamento dos estudantes é abordada por Rodrigues et al (2013, p. 117), ao afirmarem que:

$\mathrm{O}$ aluno da $\mathrm{EaD}$ em sua fase adulta, precisa igualmente de estímulo. O prazer em fazer parte de um grupo ou de empreender suas ideias através de postagens, lhe confere uma aproximação maior de todos os objetivos- os dele - e os objetivos do professor em relação ao aprender e ensinar pelo esforço da mediação subjetiva e levada à constância na sua ação pedagógica.

De forma ainda mais intensa, o estudante com deficiência demanda, de toda equipe de profissionais do curso, a elaboração de estratégias que visem sua inclusão no processo educacional. De nada adianta o acesso se não lhes for garantida a permanência e a formação de qualidade.

Nesse ponto se insere a importância da gestão democrática nos contextos que envolvem os processos de aprendizagem. Incluir nas formações e materiais institucionais as atribuições e 
possibilidades de cada um amplia a caracterização da sistemática da educação a distância, demonstrando mais sobre a modalidade e a organização institucional para que seja possível ofertar condições de aprendizagem a todos acadêmicos.

A importância da participação coletiva de todos os membros do grupo de trabalho é apontada por Lück (2009, p. 22) que os considera como:

Colaboradores diretos da construção do ambiente educacional e na qualidade da efetivação de seus processos educacionais. Sua atuação contribui de forma significativa para o trabalho educativo, tendo em vista a infraestrutura que oferecem e sua presença nos vários segmentos De seu entendimento sobre sua responsabilidade educacional depende a qualidade de seu trabalho e repercussão na formação dos alunos.

Compreendemos que a participação de todos nesse processo torna-se fundamental buscando sempre refletir de forma coletiva sobre as ações, deveres e possibilidade de cada membro do grupo. Pensar ações efetivas de inclusão destes sujeitos é uma demanda das nossas instituições, posto que os estudantes com deficiência e/ou necessidades educacionais especiais ${ }^{1}$ estão ingressando no ensino superior.

Até meados de 2013, todas as reflexões sobre inclusão no curso de Pedagogia a distância não passavam de construções hipotéticas acerca de como seria incluir um estudante com deficiência em uma modalidade de ensino que, inúmeras vezes, se depara com a difícil tarefa incluir os sujeitos nas Tecnologias Digitais da Informação e da Comunicação (TDIC). As estratégias de inclusão só começaram a ser pensadas de uma forma mais concreta quando, no processo seletivo daquele ano, a coordenação foi informada pelo Núcleo de Acessibilidade da instituição que uma estudante cega havia ingressado no curso. A equipe de trabalho se deparou com o desafio de adaptar o ambiente virtual, o polo e as metodologias de trabalho para incluir essa aluna. Na última reunião do primeiro semestre uma tutora afirmou: "Não foi tarefa fácil! " Compreende-se que é verdadeiro admitir que ainda se esteja implementando ações que garantam esse processo inclusivo. A cada semestre e disciplina o grupo vai aprendendo a fazer a partir das demandas apresentadas pelo estudante. Desde então, já ingressaram no curso, outros quatro estudantes deficientes.

Com a chegada dos estudantes com deficiência, a equipe do curso de Pedagogia adotou a postura de garantir a esses sujeitos o acesso a uma formação de qualidade e para, além disso, condições de permanência desses estudantes. Sobre o direito à educação, a recente Lei Brasileira

\footnotetext{
${ }^{1}$ Compreende-se baseado em Costas (2008) que algumas deficiências não geram necessidades educacionais especiais, amparando-se nos conceitos Vigotskianos de deficiência primária e secundária.
} 


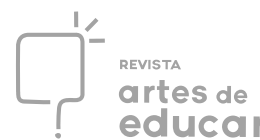

de Inclusão da Pessoa com Deficiência (Estatuto da Pessoa com Deficiência) de 2015, em seu Capítulo IV, Art. 27 apresenta:

A educação constitui direito da pessoa com deficiência, assegurados sistema educacional inclusivo em todos os níveis e aprendizado ao longo de toda a vida, de forma a alcançar o máximo desenvolvimento possível de seus talentos e habilidades físicas, sensoriais, intelectuais e sociais, segundo suas características, interesses e necessidades de aprendizagem" (BRASIL, 2015).

Ações de natureza coletiva e individual têm sido necessárias para garantir a efetivação de todo processo de inclusão. Embora seja importante considerarmos os aportes legais para o processo de democratização, não existe uma fórmula, uma receita pronta de inclusão educacional. Para cada nível e modalidade é enfatizada a necessidade de análise individual sobre o sujeito, curso, disciplina. Conforme Menezes (2006), a inclusão não é uma atribuição única dos professores, é também a responsabilidade de toda a comunidade escolar, pois incluir não é somente atentar para as questões pedagógicas e da sala de aula.

O acesso às ações do curso deve ser uma preocupação dos espaços de ensino, não somente com os estudantes matriculados, mas também para a comunidade em geral, considerando que esse é um espaço público, conforme orienta a Lei $\mathrm{n}^{\circ} 12.527$, de 18 de novembro de 2011, a qual regula o acesso a informações:

VIII - adotar as medidas necessárias para garantir a acessibilidade de conteúdo para pessoas com deficiência, nos termos do art. 17 da Lei $\mathrm{n}^{\mathrm{O}}$ 10.098, de 19 de dezembro de 2000, e do art. $9^{O}$ da Convenção sobre os Direitos das Pessoas com Deficiência, aprovada pelo Decreto Legislativo n ${ }^{\circ} 186$, de 9 de julho de 2008.

Nesse sentido, a coordenação do curso de Pedagogia a distância da UFSM, juntamente com o NTE (Núcleo de Tecnologia Educacional) e a equipe multidisciplinar, buscou alternativas e orientações sobre o uso de recursos e ferramentas mais acessíveis a esses estudantes. Foram coletadas informações via e-mail e em visitas aos polos buscando os feedbacks com os estudantes cotistas sobre as condições de acessibilidade que ocorreram desde seu ingresso.

Dentro das possibilidades do sistema, realizou-se a contratação de tutores especializados para auxiliar os estudantes nos polos onde estão alocados. Em um desses polos, em decorrência do ingresso de uma estudante surda, foi necessário que o tutor especializado também fosse fluente em LIBRAS. Apesar da sede (UFSM) dispor de um número significativo de intérpretes, a distância dos polos de apoio presencial inviabiliza o deslocamento semanal de um deles para atendimento fora da sede,. Retomando as gravações das reuniões destaca-se que uma das 
preocupações era que, na cidade do polo, não existisse ninguém com essa qualificação. Em reunião com o Núcleo de Tecnologia-NTE e o Núcleo de Acessibilidade verificou-se que a instituição ainda não havia esta demanda com discentes fora de Santa Maria-RS, ficando acordado que inicialmente seria realizada a abertura de um edital e o aguardo de candidatos para a vaga de tutor especializado. Felizmente esse temor não se concretizou, com a abertura de edital de seleção de tutor especializados vários profissionais se candidataram a vaga e foi possível realizar uma seleção criteriosa do profissional para atendimento educacional especializado do deficiente auditivo.

Inicialmente a coordenação fez uma pesquisa na legislação sobre quem deve disponibilizar o profissional especializado e não foi encontrada nenhuma menção sobre esta demanda. Somente em 2015, a DED/Capes (Diretoria de Educação a distância da Capes) incorporou às planilhas de pagamento de bolsas, a categoria de tutor para atendimento educacional especializado.

Partindo da leitura dos relatórios, visitas aos polos e entrevistas com os estudantes compreende-se que o apoio à atividade desenvolvida por esses tutores nos polos, assim como uma avaliação mais clara das peculiaridades da deficiência de cada estudante, encontrou algumas dificuldades em função da distância física entre a sede e as cidades onde esses estudantes se encontram. Algumas estratégias foram adotadas para minimizar essa situação: estabelecimento de uma parceria entre o Curso de Pedagogia e o Núcleo de Acessibilidade; visita aos polos onde os estudantes estão lotados e encontros e orientações com a equipe de professores e tutores do curso.

$\mathrm{Na}$ sede, em uma parceria entre o curso e o Núcleo de Acessibilidade foram realizadas reuniões, encaminhamentos, adequações de materiais e acompanhamento via e-mail sobre as demandas dos acadêmicos.

Com o objetivo de conhecer melhor os estudantes e verificar suas demandas individuais, foram realizadas viagens aos polos para uma avaliação mais detalhada de cada caso. Isso se fez necessário porque em muitos momentos da formação surgem demandas que são específicas do sujeito, algumas relacionadas a deficiência e outras a questões como personalidade, intimidade com o uso das TDICs, etc. Como pode ocorrer com qualquer outro estudante, em alguns casos também podem ser identificadas demandas relacionadas a organização dos estudos, implicando em um encaminhamento do sujeito para outra rede e profissionais de apoio. Compreende-se que essa avaliação é necessária para que a acessibilidade seja real e produtiva.

Outra alternativa considerada produtiva foi a realização de orientações sistemáticas com docentes e tutores, além da oferta semanal de plantões de acessibilidade para que os responsáveis 
pelas disciplinas possam adequar sua metodologia as demandas da turma. Destacamos que, em alguns casos, a disciplina necessita estar adequada para um sujeito com deficiência visual e para um surdo usuário de LIBRAS.

Siluk e Pavão (2012) apontam a necessidade de um trabalho para fortalecer as questões metodológicas para que estudantes e docentes consigam, com o uso de TDICs, aumentar o processo de interação e construção do conhecimento científico dentro do Ambiente Virtual de Aprendizagem. Manzini (2008, p.285) reflete sobre as condições de acessibilidade de uma pessoa cega:

Para que uma pessoa cega tenha acesso ao currículo, ela necessitará de que certas condições de acessibilidade estejam presentes, como por exemplo, equipamentos como ampliadores de tela, lupa eletrônica - para alunos com baixa visão - e leitores de tela, impressora braile, para alunos cegos.

Para viabilizar a inclusão de pessoas com deficiências sensoriais e os sujeitos surdos necessita-se disponibilizar serviços que sejam adequados as suas necessidades. Garcia (2008) apresenta a importância de valorização da diversidade, focando na perspectiva de construir acessibilidade para os estudantes com deficiência. $\mathrm{O}$ autor argumenta que é preciso olhar para o outro o considerando um sujeito capaz, analisando as possibilidades reais para a sua aprendizagem e autonomia. Carvalho (2008, p. 17) corrobora essa ideia, ao afirmar que:

\footnotetext{
Suas diferenças ganham conotações importantes e, como num eco, reverberam na forma na forma de preconceitos que banalizam as suas potencialidades. Tais pessoas costumam ser percebidas pelo que lhes falta, pelo que necessitam em termos assistenciais e não pelo seu potencial latente e que exige oportunidades para manifestação e desenvolvimento.
}

Precisamos considerar que antes da deficiência, há um sujeito que possui limitações e qualidades, não somente uma deficiência. Ninguém é somente surdo, somente uma mulher, ninguém é somente um diagnóstico. A eliminação de barreiras atitudinais também é proporcionada pelas ações livres de preconceitos, estigmas, estereótipos e discriminações. Manzini (2008) apresenta que as barreiras atitudinais referem-se aos processos sociais de exclusão e discriminação, diferente da exclusão ocasionada pelo ambiente físico e estrutural. Segundo esse autor, as barreiras atitudinais podem ser expressas e punidas pela Lei 7.853 de 1989, a qual dispõe sobre o apoio às pessoas com deficiência e sua integração social. Sassaki (2009, p. 6) apresenta a acessibilidade atitudinal como um processo sem preconceitos, estigmas, estereótipos e discriminações, reforçando que: 
Um ambiente escolar (e também familiar, comunitário etc.) que não seja preconceituoso melhora a autoestima dos alunos e isto contribui para que eles realmente aprendam em menos tempo e com mais alegria, mais motivação, mais cooperação, mais amizade e mais felicidade.

Nesse sentido, o curso de Pedagogia-EAD tem trabalhado para operacionalizar a inclusão em suas diferentes perspectivas e realidades. Ao longo do semestre são realizadas ações de formação e reuniões(gravadas) que objetivam compreender os desafios, demandas e situações que podem ser mais emergenciais. $\mathrm{O}$ ingresso de estudantes com deficiência também é abordado nestes momentos e com o avançar destas trocas e ações consegue-se ampliar o conhecimento sobre necessidades de adequação pedagógica, metodológica e atitudinal. Ao final da análise dos materiais coletados compreende-se que os discursos da coordenação do curso e de uma parcela significativa do corpo de professores e tutores, tem consciência de que ainda é necessário avançar em muitos passos e demandas, seja no âmbito institucional, como metodológica e culturalmente.

\section{Conclusão}

Verificamos que a inclusão não ocorre de um modo isolado, ela demanda das "ligações do dia-a-dia", das políticas e ações. No caso das pessoas com deficiência e/ou necessidades educacionais especiais, parece que nunca estiveram tão participantes na vida política e social como atualmente. É preciso pesquisar e avançar no entendimento de que se esse acesso é apenas quantitativo ou efetivo no sentido da qualidade da inserção. A modalidade a distância tem demonstrado sua força, sua possibilidade formativa e de inclusão de diferentes grupos em espaços que não lhes pertenciam. No entanto, esse pertencimento necessita ser qualificado, com suporte adequado de uma equipe que esteja preparada e disposta a buscar alternativas que visem a aprendizagem e o crescimento do outro, do grupo, do curso.

Ratifica-se que há a necessidade de um debate sobre os intérpretes nos cursos EAD, pois emergem muitas dúvidas, quanto ao financiamento e à disponibilização deste serviço. Atualmente os filmes produzidos no campus, possuem o auxílio dos intérpretes da universidade, mas nas atividades nos polos ainda não há um padrão de ações. Em muitos momentos, o número elevado de demandas no curso e a complexidade da modalidade podem gerar empecilhos, o que tem exigido uma articulação intensa entre todos os setores e atores envolvidos.

Compreende-se que, uma vez garantido o acesso, necessita-se pensar e reforçar ações e debates que busquem a permanência e aprendizagem com qualidade. O que se pretende é 
despertar um olhar atento aos estudantes que acessam a universidade respeitando as suas demandas e evitando considerá-lo apenas como um número, um dado estatístico. O olhar sobre a qualidade na formação e educação do Ensino Superior deve ser constante. É necessário avançar e, sempre de forma articulada, buscar ações e olhares que proporcionem uma reflexão significativa sobre os sujeitos incluídos, desejando vê-los crescer em seu processo de aprendizagem e sendo capazes de educar a outros. Esse processo de acesso, permanência e promoção da aprendizagem passa por várias mãos e precisa sempre ser realizado com empatia e foco, para que realmente possamos ter qualidade formativa e inclusão.

\section{Referências}

ASSOCIAÇÃO BRASILEIRA DE EDUCAÇÃO A DISTÂNCIA. Censo 2014 EAD.BR: Relatório Analítico da Aprendizagem a Distância no Brasil. Curitiba: Ibpex, 2015. Disponível em: 〈http://www.abed.org.br/censoEaD2014/CensoEAD2014_portugues.pdf >. Acesso em: 04 jan. 2018.

BARDIN, Laurence. Análise de conteúdo. Lisboa: Ed. 70, 2008.

BELLONI, M. L. Educação a distância. 1. ed. Campinas: Ed. Autores Associados, 1996. . Educação a distância. 1. ed. Campinas: Ed. Autores Associados, 1999.

BRASIL. Constituição da República Federativa do Brasil. 1988, Brasília, DF: Senado Federal.

. Código Civil. Decreto $n^{o} 5.296$ de 2 de dezembro de 2004. Disponível em:

<http://www.planalto.gov.br/ccivil_03/_ato2004-2006/2004/decreto/d5296.htm>. Acesso em: 16 fev. 2017.

Código Civil. Decreto $n^{o} 5.626$, de 22 de dezembro de 2005.

<http://www.planalto.gov.br/ccivil_03/_ato2004-2006/2005/decreto/d5626.htm>. Acesso em: 16 fev. 2017.

. Código Civil. Decreto $n^{\circ} 7611$, de 17 de novembro de 2011. Disponível em:

<http://www.planalto.gov.br/ccivil_03/_ato2011-2014/2011/decreto/d7611.htm>. Acesso em: 16 fev. 2017.

. Código Civil. Decreto $n^{\circ}$ 6.949, de 25 de agosto de 2009. Disponível em: <http://www.planalto.gov.br/ccivil_03/_ato2007-2010/2009/decreto/d6949.htm>. Acesso em: 16 fev. 2017. 
. Código Civil. Lei $n^{\circ}$ 12.527, de 18 de novembro de 2011. Disponível em:

<http://www.planalto.gov.br/ccivil_03/_ato2011-2014/2011/lei/112527.htm>. Acesso em: 16 fev. 2017

Código Civil. Lei $n^{o} 13.146$, de 6 de julho de 2015. Disponível em:

<http://www.planalto.gov.br/ccivil_03/_ato2015-2018/2015/lei/113146.htm>. Acesso em: 16 fev. 2017.

Código Civil. Lei de Diretrizes e Bases da Educação Nacional. Lei n 9.394, de 20 de dezembro de 1996. Disponível em: 〈http://www.planalto.gov.br/ccivil_03/leis/L9394.htm>. Acesso em: 25 fev. 2017.

. Código Civil. Lei $n^{\circ}$ 7.853, de 24 de outubro de 1989. Disponível em: <http://www.planalto.gov.br/ccivil_03/leis/17853.htm>. Acesso em: 13 mar. 2017.

. Ministério da Educação. Relatório da Comissão Assessora para Educação Superior a Distância (Portaria MEC n ${ }^{o}$. 335, de 6 de fevereiro de 2002). Disponível em: <http://www.portal.MEC.gov.br/sesu/arquivos/pdf/EAD.pdf >. Acesso em: 16 mai. 2017.

. Lei $n^{o} 13.146$, de 6 de julho de 2015. Disponível em: http://www.planalto.gov.br/ccivil_03/_Ato2015-2018/2015/Lei/L13146.htm>. Acesso em: 04 jan. 2018.

Secretaria de Educação Especial. Política Nacional de Educação Especial na Perspectiva da Educação Inclusiva . Brasília, DF, jan. 2008a. Disponível em: <http:// portal.mec.gov.br/arquivos/pdf/politicaeducespecial.pdf>. Acesso 04 jan. 2018.

O tradutor e intérprete de língua brasileira de sinais e língua portuguesa. Secretaria de Educação Especial. Programa Nacional de Apoio à Educação de Surdos. Brasília: MEC, 2004. Disponível em: 〈http://portal.mec.gov.br/seesp/arquivos/pdf/tradutorlibras.pdf>. Acesso em: 16 mai. 2017.

Portaria $n^{\circ} 1.679$ de 2 de dezembro de 1999. Disponível em: <http://portal.mec.gov.br/sesu/arquivos/pdf/c1 1679.pdf >. Acesso em: 16 mai. 2017.

Relatório da Educação Superior a Distância em 2002. Portaria MEC n ${ }^{\circ} 335$, de 6 de fevereiro de 2002. Disponível em: 〈http://portal.mec.gov.br/sesu/arquivos/pdf/EAD.pdf〉. Acesso em: 12 mai. 2017.

. Decreto Legislativo $n^{\circ}$ 186, de 9 de julho de 2008. Disponível em : < http://www.planalto.gov.br/ccivil_03/Congresso/DLG/DLG-186-2008.htm>. Acesso em: 04 jan. 2018.

CARVALHO, A. P. Apresentação (2007). In. MINISTÉRIO PÚBLICO DO RIO GRANDE DO NORTE. Acessibilidade: projetando e construindo cidadania. Cartilha de Orientação. Natal, 2007. Disponível em: 〈http://www.keroul.qc.ca/DATA/PRATIQUEDOCUMENT/101_fr.pdf〉. Acesso em: 12 mai. 2017.

CRESWEL, J. W. Projeto de pesquisa: método qualitativo, quantitativo e misto. 2. ed. Porto Alegre: Artmed, 2007. 
CORRÊA, J. Educação a distancia: orientações metodológicas. Porto Alegre: Artmed, 2007.

COSTAS, F. A. T. Educação inclusiva: reflexões acerca do processo e da nova política nacional. Revista Educação Cidadã , Santa Maria, v. 1, n. 1, p. 16, 2008

DENZIN, N. K.; LINCOLN, Y. S. Introdução: a disciplina e a prática da pesquisa qualitativa. In: DENZIN, N. K.;LINCOLN, Y. S. (Orgs.). O planejamento da pesquisa qualitativa: teorias e abordagens. 2. ed. Porto Alegre: Artmed. 2007.

GARCIA, R. M. C. Políticas inclusivas na educação: do global ao local. In: BAPTISTA; C. R.; CAIADO, K. R. M.; JESUS, D. M. (Org.). Educação especial: diálogo e pluralidade. 1. ed. v. 1. Porto Alegre: Mediação, 2008.

GERHRDT; et al. Métodos de pesquisa. Universidade Aberta do Brasil - UAB/UFRGS e pelo Curso de Graduação Tecnológica - Planejamento e Gestão para o Desenvolvimento Rural da SEADEAD/UFRGS. Porto Alegre: Editora da UFRGS, 2009.

GIL, A. C. Como elaborar projetos de pesquisa. 4. ed. São Paulo: Atlas, 2002.

GUAREZI, R. C. M.; MATOS, M. M. Educação a distância sem segredos. Curitiba: Editora Ibpex, 2009.

LIMA, K. R. S. A política de ensino superior a distância no Brasil nos anos de neoliberalismo doi: 10.5007/2175-795X.2011v29n1p19. Perspectiva, [s.1.], v. 29, n. 1, 24 out. 2011. Universidade Federal de Santa Catarina (UFSC). <http://dx.doi.org/10.5007/2175795x.2011v29n1p19>.

LÜCK, H. Dimensões de gestão escolar e suas competências. Curitiba: Editora Positivo, 2009.

MACIEL, A. M. R.; CECHIN, A. F.; NOGUEIRA, V. S. Atributos de um Educador: concepções prévias de professores ingressantes na educação profissional e tecnológica. Revista de Educação Técnica e Tecnológica em Ciências Agrícolas, v. 2, p. 1-19. Disponível em: <http://www.portalanpedsul.com.br/admin/uploads/2010/Formacao_de_Professores/Trabalho/01 18 10_ATRIBUTOS_DE_UM_EDUCADOR CONCEPCOES_PREVIAS_DE_PROFESSO RES_INGRESSANTES_NA_EDUCACAO_PROFISSIONAL_E_TECNOLOGICA.PDF>.

Acesso em: 12 mai. 2017.

MANZINI, E. J. Desafios da inclusão do aluno com deficiência na escola. In. MANZINI, E. J. Inclusão do aluno com deficiência na escola: os desafios continuam. Marília: ABPEE/FAPESP, 2007.

MENEZES, E. C. P. Informática e Educação Inclusiva: discutindo limites e possibilidades. 1. ed. v. 1. Santa Maria: Editora da Universidade Federal de Santa Maria, 2006.

MINISTÉRIO DA EDUCAÇÃO. Universidade Federal de Santa Maria. Resolução N. 011/07, de 3 de agosto de 2007. Disponível em: 〈http://w3.ufsm.br/afirme/images/011-07.pdf>. Acesso em: 12 mai. 2017. 
NOGUEIRA, V. S. Relações sociais de reconhecimento intersubjetivo virtual na formação de professores a distância. Pelotas, 2016. Tese. (Doutorado em Educação). Programa de Pós Graduação em Educação - Universidade Federal de Pelotas.

SASSAKI, R. K. Inclusão: construindo uma sociedade para todos. 8. ed. Rio de Janeiro: WVA, 2010.

. Inclusão: acessibilidade no lazer, trabalho e educação. Revista Nacional de Reabilitação (Reação), São Paulo, Ano XII, mar./abr. 2009.

SILUK, A. C. P.; PAVÃO, S. M. O. A formação de professores a distância: ser professor na contemporaneidade - deveres e fazeres na educação especial. In: SILUK, A. C. P. (Org.). Atendimento educacional especializado: contribuições para a prática pedagógica. 1. ed. Santa Maria: UFSM, Centro de Educação, Laboratório de Pesquisa e Documentação.

${ }^{i}$ Graduada em Educação Especial. Mestre e doutoranda em Educação na Universidade Federal de Santa Maria (UFSM).

${ }^{\text {ii }}$ Professora Associada do Departamento de Fundamentos da Educação da Universidade Federal de Santa Maria (UFSM).

iii Associação Brasileira de Educação a Distância. Disponível em: <http://www.abed.org.br/site/pt/>. Acesso em 04 jan 2018. 